\title{
Research on Urban Ecological Landscape Design
}

\author{
Wenrui Zhang ${ }^{1}$ \\ ${ }^{1}$ Lanzhou Jiaotong University, Lanzhou, Gansu, 730070
}

KEYWORDS: Urban; Ecological Landscape; Design

\begin{abstract}
Urban ecosystems are human beings in the transformation and adaptation to the natural environment in the process of urban residents and the surrounding environment interaction set up artificial ecosystem is Nature - Economy - Society complex systems. Cities occupy a certain geographic space, it has a unique biotic and socio-economic factors. City view these elements through the material and energy metabolism, biogeochemical cycles, as well as material supply and waste disposal process, interrelated continuum has a certain composition, structure, spatial pattern and dynamics characteristics together to form.
\end{abstract}

\section{Introduction}

Cities with the development of human society gradually developed geospatial, is human transformation and adapt to the natural environment in the process, build up the natural, economic, social and complex ecosystem. Urban landscape through a variety of elements of material and energy metabolism, biogeochemical cycles, as well as material supply and waste disposal process, the mosaic together with a specific structure, the unity of functions and services, with the dominant human, ecological fragility, broken and other characteristics. In recent years, the rapid development of urbanization leading to the urban landscape has undergone tremendous changes, how to build the harmony between man and nature of urban ecological landscape have been scholars, designers, government and public attention. The existing landscape of urban ecology connotation and the lack of uniform quantitative criteria, resulting in the presence of input-output efficiency ecological landscape, market acceptance and other uncertainties become one of the main impacts of further promotion of ecological landscape.

\section{The Basic Connotation of Urban Ecological Landscape}

Ecological landscape understanding and standards in the field of forestry, landscape ecology, architecture, urban planning, etc. have different emphases. In the study of forest, often as the main vegetation landscape or vegetation green landscape in lieu of that; in landscape ecology research, it refers to the biological and cultural landscape that contains features, as distinguished from the general vision of the landscape, with specific ecological functions and services landscape; it is often associated with the architecture of traditional Chinese theory combined emphasis on "Heaven" and environmental protection; in urban or regional planning and research resources and environment, ecological landscape refers to is the result of ecological planning or design sustainable, harmony between man and nature landscapes.

From the 19th century, foreign Howard garden city views, to the mid-20th century Mcharg design with nature, have emphasized the landscape design near natural or naturalized, its core is based on regional resources and environmental characteristics, combined with ecological suitability 
analysis, human development activities corresponding. Foreman and other late 20th century (Forman) proposed landscape ecological planning and ecosystem management ideology, emphasizing the control and influence of landscape spatial patterns and processes in order to achieve the goal of sustainability planning. In China, Ma Shijun and other famous scholars have raised the ideological landscape ecological planning of natural and human harmony. And traditional ecological planning approach centered on different natural landscape ecological planning explicitly humans and their activities as an integral part of the landscape as a whole, rather than independent elements of a landscape. Referred to herein are based on urban ecological landscape ecology, the concept of landscape architecture and urban planning, landscape planning and design of landscape spatial units or a combination of space, is the product of landscape ecological planning, it refers to a human ecology participation under the influence healthy and sustainable standard artificial landscape management and landscape.

So far, the quantitative evaluation of urban ecological landscape of the lack of uniform principles and standards, but also limits its further promotion and practice. International Interior Design Association (International Interior Design Association, IIDA) survey of 100 interior designers also found that $83 \%$ of respondents believe that to provide customers with sustainable solutions is a fundamental obligation, but only $37 \%$ the project introduces a quantitative ecological landscape plan, the biggest problem is the lack of scientific respondents proposed guidelines, not enough time, and no studies have shown that ecological landscape can bring economic benefits. Cassidy [14] survey also found that the degree of market acceptance and cost is the biggest obstacle to the promotion of ecological landscape. US Green Building Council (The First Green-build conference, sponsored by the US Green Building Council) also summarized the challenges facing the ecological landscape practices, including high initial cost (78\%), difficult to determine the cost of investment and long-term economic benefits (47\%), new technologies are not suited (39\%), the lack of market acceptance (24\%) and the like. Smida for a material ecological landscape design conducted a survey and found that 68 percent of respondents use some green material, these respondents believe that the difficulties faced by the use of green materials include: customer demand is not high (37\%), materials availability of low (21\%) and high costs (14\%), is not easy to determine whether the green material (23\%).

\section{The Elements of City Ecological Landscape}

For a city within the city landscape elements of different sizes and properties according to their structural features can be divided into spatial matrix, plaques and corridor categories.

The main urban landscape is all kinds of built-up areas, a variety of different functions, the nature and shape of the building, the urban landscape clearly different from other landscapes. Urban road network to link the buildings together so that both urban neighborhoods with a high degree of connectivity, but also has the advantage of a higher degree. Therefore, we have seen urban neighborhoods and other cities urban landscape matrix.

Urban Landscape plaque refers to relatively homogeneous area or spatial entities with different functions and properties. It has a major impact on the urban landscape ecology properties of landscape elements plaques, including city parks, urban green space and a small piece of woodland.

City corridor is linear landscape elements in the urban landscape or ribbon, among which network traffic constituted the main line. Rivers, ditches, forest, streets and other corridors, have a significant impact on the urban landscape ecology properties. Urban landscape of these corridors, often urban landscape material, energy, information, and biological diversity centralized collection or where maintenance of the urban landscape function has a special role. 


\section{The Features of Urban Ecological Landscape}

Human activities strongly affect the natural conditions of the urban landscape, hydrology, meteorological characteristics, surface structure, and other flora and fauna. Urban landscape features, largely reflects the local socio-economic development and historical and cultural characteristics, but also the performance of the human reality of the dream ideal living environment. In the urban landscape, the major structural component of the overall pattern and landscape, are arranged or artificially adjust artificial off, several key ecological processes, also in artificially control or impact; the urban landscape features human needs maintain.

Urban landscape ecological processes mainly rely on human input or output different nature of energy and matter to coordinate and maintain. With the changes in social and economic development, political and cultural factors, urban landscape changes fast, especially with marginal changes in the urban landscape is particularly evident. As urban landscape system is highly dependent on human control, the city's natural ecological processes is greatly simplified and fragmentation, continuity and integrity of urban functions are very fragile, and once human activity disorders, easily lead to urban functions, especially in urban ecological decline, overall sustainability and amenity of the city will decline.

Ease of access within the city, throughout the landscape, the city will cut into many different sizes plaques, farmland and natural vegetation landscape with large areas of continuous distribution in stark contrast. Because between the complexity of the urban landscape and urban landscape elements patch diversity of human activities between the urban landscape and its features and just outside the city, associated with human activities is very high energy and material circulation rate, and the Urban Landscape " natural "ecological processes blocked, improve the urban landscape ecological connectivity, will become the basis for the maintenance of ecological processes and environmental functions of urban landscape.

\section{The Design Principles of Urban Ecological Landscape}

First of all, human life continues to receive all the necessary water, food, energy from the environment and so on. Living space the plants and trees are the result of long-term human interaction with the natural environment. Since the disappearance of species has become the most important contemporary environmental issues. Not only native species most suitable for the local growing, and management and maintenance costs low. To be based on local native materials, protection and the establishment of diverse native habitats urban ecological system design.

Secondly, the need may be related to the modern history of the property and the people's needs vary. The new design should form the basis of the natural process of accommodation, according to the place of the sun, terrain, water, air, soil, vegetation, and energy and so on. The design process is to place these natural factors with integration features into the design, maintaining a healthy workplace, to adapt to places of natural ecological processes. Therefore, the urban ecological design, the need to respect cultural traditions and native habitat system, consider the revelation given to local or traditional cultural characteristics of urban ecological design.

To achieve sustainable development of the human environment must be protected and economical use of non-renewable resources. Even renewable resources, their regenerative capacity is limited, and therefore their use also needs to adopt a manner guaranteed to take the information to be used. In large-scale urban development, protection of special natural landscape elements or ecosystems utmost is important. 
Natural ecosystems to sustain human life and meet their needs to provide a variety of conditions and processes, ecosystem services, including: clean air and water; climate regulation; mitigation of floods and droughts; degradation and detoxification of waste; create and regenerate soil and soil fertility; maintaining biodiversity. Nature provides human service is comprehensive, so naturally acting this design principle emphasizes symbiosis and cooperation between man and the natural ecological processes, through cooperation with the process of life and patterns followed, reduce the ecological impact of urban design.

Landscape ecology is a revealed language, prompted us to return to the ancient art. Eco-design responds to people on land and on the biological attachment relationships, and elements of nature and the natural process by exposure and guide people to experience nature to awaken people to the natural care. Nature is revealed as an important ecological and aesthetic principles of ecological design principles in modern landscape design more and more attention, a national landscape design exhibition held recently at the University of Illinois in the United States, then this theme, is called ecological reveal the design, "that reveal and explain ecological phenomena, processes, and relationships of landscape design." Emphasize not only landscape designers landscape design of form and function, highlighting its characteristics, to guide people's vision and movement, people design experience. In the natural landscape of water and fire are no longer as a disaster, but a landscape to maintain ecological processes and biological diversity are required.

\section{Conclusion}

Construction of ecological landscape in harmony with nature is one of the important goals of today's urban development, the unity index system of urban ecological landscape planning and design of the urgent needs. By summarizes the basic content and main characteristics of urban ecological landscape that includes its core values of sustainability, ecological and economic harmony. In short, eco-design to urban ecology urban design point of view, in the design process, make full use of the matrix, patches and corridors, allowing natural acting to maintain the integrity of the natural landscape and urban continuity. Promote the sustainable development of the city.

\section{REFERENCE:}

[1] Wu Xi. Urban ecological landscape and ecological landscape design. Ecological Economy, 2005, (10): 256-259.

[2] Jun Gao. Application of Landscape Ecology in urban planning and management. Advances in Earth Science, 2001,16 (6): 813-820.

[3] Fu Bojie, Chen Liding. Landscape Ecology Principles and Applications (Second Edition). Beijing: Science Press, 2011.

[4] Gao Jixi, Tianmei Rong. Urban Community Development Model Sustainable "ecological community" Discussion. China Development, 2007,7 (4): 6-10.

[5] Chen Shuang, Wang Jin. Ecological Landscape and Urban Form Integration. Progress in Geography, 2004,23 (5): 67-77. 